\title{
O perfil dos profissionais da Unidade de Apoio à Família dos núcleos de atividades de altas habilidades/superdotação'
}

\author{
Viviane Tramontina Leonessa* \\ Maria Cristina Marquezine**
}

\section{Resumo}

A pesquisa objetivou traçar o perfil do profissional que atua na Unidade de Apoio à Família dos Núcleos de Atividades de Altas Habilidades/Superdotação, identificando a formaçáo inicial e continuada para o atendimento da família e dos alunos com Altas Habilidades/Superdotação, assim como as dificuldades ou necessidades vivenciadas no trabalho. Como o tema proposto é pouco frequente na literatura, a pesquisa configurou-se como Survey. Foram participantes onze NAAH/S, representados pelos coordenadores da unidade pesquisada. $\mathrm{O}$ instrumento de coleta dos dados foi um questionário eletrônico enviado a todos os núcleos por email. O questionário foi elaborado com o auxílio de duas fontes: o Documento Orientador e os dados de entrevistas realizadas com pesquisadoras na área. Os dados receberam tratamento quali-quantitativo, ou seja, as questôes objetivas receberam tratamento estatístico e as informaçóes subjetivas foram agrupadas em temas de análise criados a partir dos conteúdos das respostas apresentadas nas questôes, denominadas análise de conteúdo. Os principais resultados demonstraram que os profissionais que atuavam nas unidades eram, em sua maioria, pedagogos e psicólogos, mas existiam também outras formaçôes, que iam do ensino médio/técnico a outros cursos superiores. Apesar de a grande maioria possuir cursos de formação continuada, poucos informaram ter formaçáo específica para o atendimento à família de pessoas com AH/SD. Dentre as dificuldades vivenciadas, destacam-se a falta de formaçáo para o atendimento à família, ausência de recursos materiais e financeiros e de parcerias com universidades.

Palavras-chave: Educação Especial; Altas habilidades/superdotação; Núcleo de atividades de altas habilidades/superdotação; Família.

* Mestranda em Educação pela Universidade Estadual de Londrina, Londrina, Paraná, Brasil.

** Professora doutora da Universidade Estadual de Londrina, Londrina, Paraná, Brasil. 


\section{The profile of professionals of Unit for the Family in the Core of Activities for High Abilities/Giftedness}

\section{Abstract}

This research meant to define the profile of professionals in the NAAH/S - a Support Unit for the Family in the Core of Activities for High Abilities/Giftedness, identifying their original graduation and qualification courses to support the families and students with high abilities/giftedness, as well their needs and difficulty on the jobs. As there this theme was not very often on the literature this study was defined as a Survey. Eleven NAAH/S, represented by their unit coordinators, were researched. The instrument of data collection comprehend an electronic questionnaire sent to the all cores by e-mail, and it was elaborated with the aid of two sources: the guiding document and data from interviews with researchers from area. The data were treated qualitatively and quantitatively, that is, the objective questions were submitted to descriptive statistics and subjective questions were grouped in categories of analysis according to their contents and treated as content analysis. Main results evidenced that most professionals were pedagogues and psychologists, other professionals were graduates from secondary or technical schools or from other type of higher education. Even though, the most have qualification courses a few of them had specific qualification for the services of assisting families of students with high abilities/giftedness. Among the difficulties experienced, there are a lack of qualification to support the families, materials and financial restrictions, and lack of partnership with higher education institutions.

Keywords: Special education; High abilities/giftedness; NAAH/S - Core of activities for high abilities/giftedness; Family.

\section{Introdução}

Segundo o Documento Orientador: Execuçáo da Ação, o Núcleo de Atividades de Altas Habilidades/Superdotação (NAAH/S) não é apenas um serviço baseado em modelos já estabelecidos, mas um espaço para a reflexão e elaboração de açôes de implementação das políticas de inclusão, cujo objetivo é:

$$
\begin{aligned}
& \text { [...] atender os alunos com altas habilidades/superdotação; pro- } \\
& \text { mover a formação e capacitaçáo dos professores e profissionais da } \\
& \text { educaçáo para identificar e atender a esses alunos; oferecer acom- } \\
& \text { panhamento aos pais dessas crianças e à comunidade escolar em } \\
& \text { geral, no sentido de produzir conhecimentos sobre o tema e disse- } \\
& \text { minar informaçóes e colaborar para a construçáo de uma educaçáo } \\
& \text { inclusiva e de qualidade. (BRASIL, 2006, p. 11). }
\end{aligned}
$$

Para que se possa formar uma unidade, o Ministério da Educação (MEC) propóe que todos os NAAH/S tenham a mesma denominaçáo e utilizem o mesmo logotipo, acatando também a estrutura proposta para o serviço, que oferece três unidades de atendimento: a Unidade de Atendimento ao Aluno, a Unidade de Atendimento 
ao Professor e a Unidade de Apoio à Família, havendo em cada uma delas, funções e profissionais específicos, conforme o Documento Orientador de implantação dos núcleos (BRASIL, 2006).

A Unidade de Apoio à Família (UAF), objeto do presente estudo, consiste em "[...] prestar orientação e suporte psicológico e emocional à família, com vistas à compreensão do comportamento dos seus filhos, melhorando as relações interpessoais e incentivando o desenvolvimento das potencialidades dos alunos [...]" (BRASIL, 2006, p. 25). A proposta de oferecer atendimento à família do aluno com Altas Habilidades/Superdotação (AH/SD) pode ser considerada um suplemento que corrobora os objetivos da Política Nacional de Educaçáo Especial na Perspectiva da Educação Inclusiva (BRASIL, 2008). Nela afirma-se a importância da participação da família e da comunidade no processo de inclusão e atendimento às necessidades educacionais especiais do aluno. O Decreto $\mathrm{n}^{\mathrm{0}} 7.611 / 2011$, em seu artigo segundo, vem ratificar o documento supracitado ao explicitar

$\mathrm{O}$ atendimento educacional especializado deve integrar a proposta pedagógica da escola, envolver a participação da família para garantir pleno acesso e participaçáo dos estudantes, atender às necessidades específicas das pessoas público-alvo da educação especial, e ser realizado em articulação com as demais políticas públicas. (BRASIL, 2011).

Observa-se, através da literatura especializada (ASPESI, 2007; SILVA, FLEITH, 2008; SAKAGUTI; BALSANELLO, 2012), a importância dos profissionais especializados oferecerem informaçôes e orientaçôes, quando a família do aluno com AH/SD está vivenciando dificuldades relacionadas: à sua compreensão das $\mathrm{AH} / \mathrm{SD}$, das características e das áreas de interesse do filho, à maneira como lidar com as próprias expectativas diante do talento do filho, ao atendimento educacional especializado (AEE) e da classe comum oferecido ao filho, a sua participação na educação do filho, além de outras. Açốes como estas poderão contribuir para o desenvolvimento cognitivo, afetivo e social da pessoa com $\mathrm{AH} / \mathrm{SD}$, para o relacionamento familiar e para o estabelecimento de parceria colaborativa entre a família e a escola, beneficiando todos os envolvidos e a sociedade em geral, visto que essa parceria poderá fortalecer o atendimento na área e contribuir para a ampliação das políticas públicas.

Frente a realidade aqui exposta, esta pesquisa teve por objetivo traçar o perfil do(s) profissional(is) que atua(m) na UAF dos NAAH/S dos estados da Federação e Distrito Federal, identificando a formação inicial e continuada para o atendimento da família e dos alunos com AH/SD, assim como as dificuldades ou necessidades vivenciadas no trabalho.

\section{Método}

\section{Descrição dos participantes}

Participaram do estudo 11 (40.74\%) dos 27 NAAH/S distribuídos nos estados brasileiros e Distrito Federal, representados pelos coordenadores da UAF. Destes participantes coordenadores, verificou-se que todos (100\%) eram do gênero feminino, com idade média de 44 anos, sendo mínima de 27 e máxima de 61 anos. 


\section{Descrição dos instrumentos e materiais}

O instrumento utilizado foi um questionário eletrônico com questôes abertas e fechadas, criadas no aplicativo denominado "Formulário" do Google Drive, enviado por meio do endereço eletrônico dos NAAH/S. A elaboração do questionário teve como referência o Documento Orientador: Execução da Ação (BRASIL, 2006), que subsidiam a implantação, organizaçáo e as açôes dos NAAH/S, e os dados de entrevistas realizadas com três pesquisadoras de renome nacional na área de AH/SD.

Após sua elaboração, foi submetido à apreciação de juízes, sendo também realizado um estudo-piloto com duas profissionais da área de AH/SD. O instrumento final constou de 19 questôes, divididas em quatro temas: a) informaçóes gerais sobre o NAAH/S, a UAF e os profissionais que fazem parte dessa unidade; b) formação inicial e continuada dos profissionais da UAF; c) objetivos da UAF; d) atividades realizadas pela unidade e e) avaliação do próprio instrumento. Como o presente artigo é um recorte de um estudo maior, serão apresentadas apenas as questôes dos itens a e b.

\section{Procedimento metodológico}

O tipo de pesquisa adotada configurou-se como Survey. Para Babbie (2005), os métodos de survey são importantes quando se está começando a investigação de algum tema, pois podem fornecer caminhos para pesquisas futuras. Como não foram encontradas pesquisas sobre o atendimento à família nos NAAH/S, a escolha desse procedimento foi considerada a mais adequada.

\section{Tratamento e análise dos dados}

Como o instrumento de coleta dos dados possuía questôes objetivas e dissertativas, os dados receberam tratamento quali-quantitativo (MARQUEZINE, 2006). As questōes objetivas receberam tratamento estatístico e as informaçóes subjetivas, ou seja, as respostas elaboradas pelos participantes foram agrupadas em temas de análise, com base nos conteúdos das respostas apresentadas nas questôes, denominada análise de conteúdo, conforme orientam Bardin (1977) e Marquezine (2006).

\section{Resultados e discussão}

Conforme o Documento Orientador (BRASIL, 2006), a equipe profissional do NAAH/S pode ser organizada conforme a realidade de cada estado, desde que seja respeitado o perfil dos profissionais indicados para cada unidade de atendimento que o compóe. Em relação aos profissionais que atuavam nas UAF, na época da coleta dos dados, foi verificado que haviam 38 profissionais distribuídos nos onze NAAH/S que participaram do estudo, como demonstra o gráfico a seguir. 


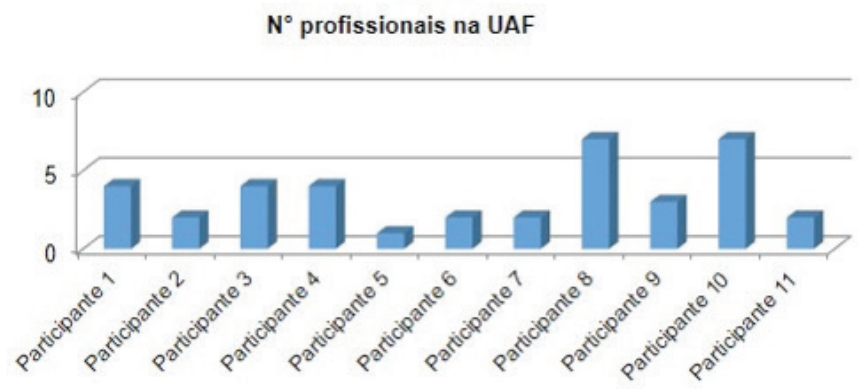

Foi verificado que uma das UAF dos NAAH/S participantes (participante 5), tinha apenas um profissional responsável pelo serviço. Quatro UAF (participantes 2, 6, 7 e 11) possuíam, em seu quadro, dois profissionais cada e, com uma equipe formada com três profissionais, encontrava-se o participante 9. Três UAF (participantes 1,3 e 4) contavam com uma equipe de quatro profissionais cada e duas UAF (participantes 8 e 10) possuíam um grupo de sete profissionais cada.

Os dados indicaram que há diferenças em relação ao número de profissionais disponibilizados para as UAF dos NAAH/S e, frente a esse fato, duas hipóteses podem ser presumidas. A primeira delas seria de que a demanda de famílias atendidas estaria influenciando na formação da equipe das UAF dos NAAH/S participantes. Infelizmente não foram coletados, no presente estudo, dados sobre o número de famílias e alunos com AH/SD atendidos nos núcleos participantes, que poderiam confirmar essa suposição.

A segunda hipótese, talvez a que mais se aproxima dos resultados obtidos no estudo, seria a carência de investimentos dos órgãos responsáveis pelos núcleos. A Tabela 3, que será apresentada posteriormente, evidenciou que as dificuldades vivenciadas pelos profissionais das unidades estavam na falta de recursos materiais, financeiros e de formação inicial e continuada. Se os NAAH/S apresentavam dificuldades como estas, pode-se considerar que a disponibilização de recursos humanos também pode ser algo difícil de ser conquistado. É importante ressaltar, que, apesar da disparidade entre as unidades dos NAAH/S participantes, no que se refere ao número de profissionais componentes da equipe que trabalha com a família, não é a quantidade que dará qualidade ao atendimento, mas sim o planejamento e delineamento realizados para a efetivação desse trabalho.

Em se tratando da formação desses profissionais que atuavam nas UAF, os dados demonstrados na Tabela 1 indicaram que três profissionais (8\%) possuíam ensino médio ou técnico, dois (5\%) eram assistentes sociais, 13 profissionais (34\%) possuíam formação em pedagogia, 17 (45\%) eram graduados em psicologia e três profissionais $(8 \%)$ possuíam outra formação, nas áreas de artes plásticas e licenciaturas em letras e língua estrangeira, de acordo com informações coletadas pelos participantes. 
Tabela 1 - Formação inicial dos profissionais que atuavam na UAF dos NAAH/S.

\begin{tabular}{l|l|l}
\hline Formação inicial dos professores da UAF dos NAAH/S & N $^{\circ}$ & \multicolumn{2}{l}{} \\
\hline Ensino médio/técnico & 3 & $8 \%$ \\
\hline Assistente Social & 2 & $5 \%$ \\
\hline Pedagogia & 13 & $34 \%$ \\
\hline Psicologia & 17 & $45 \%$ \\
\hline Outro & 3 & $8 \%$ \\
\hline TOTAL & 38 & $100 \%$ \\
\hline
\end{tabular}

As informações acima descritas induzem à suposição de que algumas das UAF dos NAAH/S participantes poderiam não possuir, em seu quadro, o profissional indicado pelo Documento Orientador (BRASIL, 2006), que é o psicólogo, ou psicopedagogo. Vale destacar que, no Brasil, a formação em psicopedagogia é bastante procurada em cursos de especializaçáo e pode ser realizada por psicólogos, pedagogos ou outro profissional da área da educação ou saúde, como por exemplo, o fonoaudiólogo e o terapeuta ocupacional, sendo entấo compreendida como área da atuação e não de profissão. O Projeto de Lei da Câmara N ${ }^{\circ} 31$ de 2010, elaborado pela deputada professora Raquel Teixeira, propóe a regulamentação da profissão, entretanto, ele ainda permanece em discussão.

Diante desses fatores e sabendo-se que muitos dos objetivos da UAF dos NAAH/S são da ordem da atuação do psicólogo, sobre o segundo profissional indicado pelo Documento Orientador (BRASIL, 2006), o psicopedagogo, pode-se questionar sobre como seriam realizadas algumas atividades, especialmente a avaliação por testes psicométricos e a oferta de suporte psicológico e emocional à família, quando o psicopedagogo da UAF possui outras formaçóes iniciais que não da psicologia. Talvez seja necessário, em outro momento, que se faça uma análise mais aprofundada sobre as orientaçóes estabelecidas no documento acima descrito para que os objetivos a serem alcançados, as açôes a serem realizadas e os profissionais que compóem a equipe sejam condizentes.

Outros questionamentos referentes à Tabela 1 podem ser levantados. O primeiro deles seria compreender a finalidade da UAF possuir, em sua equipe, profissionais com formação nas licenciaturas em artes plásticas, letras e língua estrangeira. Outra questão seria sobre a função dos profissionais cuja formaçáo inicial é ensino médio ou técnico. Por fim, tendo-se como referência os objetivos da UAF descritos no Documento Orientador (BRASIL, 2006), como se daria o trabalho de um assistente social? Quais açóes estariam sendo efetivadas, além das propostas do referido documento, diante da participaçáo do assistente social e de outros profissionais? Ressalta-se que, ao analisarem-se os dados de modo individual, ou seja, por participante, foi possível verificar que nove UAF (82\%) dos NAAH/S possuíam, em seu quadro de pessoal, o psicólogo.

Retomando-se a formaçáo dos profissionais da UAF, constatou-se no Documento Orientador (BRASIL, 2006), que os profissionais devem possuir conhecimen- 
to na área de $\mathrm{AH} / \mathrm{SD}$, formação ou experiência na área educacional e de atendimento à família. A Tabela 2 mostra o nível de formação complementar em educação especial ou área correlata dos profissionais que compóem a UAF dos NAAH/S participantes.

\begin{tabular}{l|l|l}
\hline Formação complementar dos profissionais da UAF & $N^{\circ}$ & $\%$ \\
\hline
\end{tabular}

Tabela 2 - Formação complementar dos profissionais que atuavam na UAF dos NAAH/S.

\begin{tabular}{l|l|l}
\hline Cursos de capacitação & 17 & $45 \%$ \\
\hline Especialização & 17 & $45 \%$ \\
\hline Mestrado & 3 & $8 \%$ \\
\hline Doutorado & 0 & $0 \%$ \\
\hline Pós Doutorado & 0 & $0 \%$ \\
\hline Não possui formação complementar & 1 & $2 \%$ \\
\hline TOTAL & 38 & $100 \%$ \\
\hline
\end{tabular}

De acordo com os dados, $45 \%$ dos profissionais da UAF possuíam, como maior nível de formação, cursos de capacitação. Outros 45\%, conforme informado pelos participantes, realizaram cursos de especialização lato sensu, $8 \%$ possuíam formação stricto sensu, em programas de mestrado, e $2 \%$ não realizaram qualquer tipo de formação em educação especial ou área correlata. Esse dado pode ser considerado muito positivo, pois um total de $98 \%$ dos profissionais, que atuavam na UAF, possuíam formação em educação especial ou área correlata; entretanto, será que essa formação lhes forneceu suporte ou conhecimento suficiente para atuarem na área das $\mathrm{AH} / \mathrm{SD}$, mais especificamente no atendimento à família?

Comumente, os cursos de formação lato sensu em educação especial estão direcionados para uma formação inclusiva que aborda todas as áreas que compóem a educação especial brasileira (as deficiências, os transtornos globais do desenvolvimento e AH/SD). De acordo com o Projeto Político Pedagógico de Curso de Especializaçáo Lato Sensu em Atendimento Educacional Especializado - AEE (BRASIL, 2009/2010, p. 3), ofertado pelo MEC, essa formaçáo “[...] têm como eixo orientador o AEE, que se caracteriza como uma ação da educação especial voltada para a promoção da acessibilidade". Sua proposta é formar professores para realizar o atendimento nas Salas de Recursos Multifuncionais (SRM). Possivelmente, a questão da família e a importância de lhe serem ofertados serviços de atendimento, caso sejam abordadas nesses cursos, sáo-no de modo superficial e insuficiente para o trabalho a ser alcançado pelas UAF dos NAAH/S.

Em relação aos programas de pós-graduação stricto sensu, verificou-se que são poucas as ofertas de estudo direcionado às AH/SD (CIANCA; LYRA; MARQUEZINE, 2010; PÉREZ, 2006), dado que é confirmado quando se observa o pequeno número de publicaçóes disponíveis no banco de teses e dissertaçôes da CAPES e nas revistas científicas. 
Uma das questóes do instrumento de coleta de dados, foi perguntado aos participantes se os profissionais da UAF tiveram alguma formação específica para o atendimento à família de pessoas com AH/SD. As respostas dos participantes revelaram que apenas três (27\%) unidades dos NAAH/S pesquisados tinham em sua equipe profissionais que receberam tal formação. Outros sete participantes (64\%) afirmaram não possuir formação para o atendimento da família e um participante (9\%) não respondeu à questão.

Esses dados evidenciaram que a formação de grande parte desses profissionais pode ser insatisfatória em relação às atividades e açōes que devem ser realizadas na unidade. Talvez as características e necessidades dessas famílias, o modo como elas concebem as $\mathrm{AH} / \mathrm{SD}$ e os comportamentos dos filhos, possam receber pouca atenção por parte da unidade. Consequentemente, as contribuiçóes que essas ações poderiam proporcionar para o desenvolvimento dos alunos atendidos e para seus contextos familiares possam estar aquém do esperado.

Os participantes que afirmaram que a UAF, em que atuam, possui profissionais com formação para o atendimento à família do indivíduo com AH/SD, destacaram um curso realizado em Brasília/DF, promovido pelo MEC. Pelo que se tem conhecimento, esses cursos ocorreram nos anos de 2004 e 2006, período em que se iniciou o movimento de implantaçáo dos NAAH/S. Foram reunidos profissionais e gestores dos estados e Distrito Federal para a formação de multiplicadores que realizariam a capacitação dos demais profissionais de sua regiáo. Nenhum outro curso foi mencionado pelos participantes.

O presente dado mostrou que a formação que deveria acontecer por meio dos multiplicadores que participaram da capacitação ofertada pelo MEC, parece não ter sido efetivada em todos os estados. Será que os profissionais e gestores que tinham a responsabilidade de repassar o conhecimento aos demais profissionais que atuavam com as AH/SD simplesmente não o fizeram? Será que guardaram o conhecimento para si, ignorando a necessidade da formação para o exercício do trabalho? Ou será que a formação possa ter ocorrido em serviço, sem certificação de curso e então esta não foi considerada uma formação para os participantes do estudo? Talvez seja importante investigar, em futuras pesquisas, a eficácia dos cursos de formação de multiplicadores proposto pelo governo aos estados e municípios no sentido de verificar se tais cursos têm o direcionamento devido.

$\mathrm{Na}$ Tabela 3, apresentada a seguir, foi possível verificar que a maioria dos participantes afirmou que seus profissionais enfrentavam diversas dificuldades no ambiente de trabalho. Quanto a essas dificuldades, constatou-se que, para 73\% dos participantes, elas se referem à necessidade de formação inicial e continuada em AH/ $\mathrm{SD}$, assim como de formação direcionada ao atendimento à família da pessoa com AH/SD, também indicado por $73 \%$ da população participante. 
Tabela 3 - Dificuldades/necessidades vivenciadas pelo(s) profissional (is) da UAF dos NAAH/S.

\begin{tabular}{l|c|c}
\hline Dificuldades ou necessidades dos profissionais da UAF & N $^{\circ}$ & $\%$ \\
\hline Formação inicial e continuada sobre AH/SD. & 8 & $73 \%$ \\
\hline Formação específica sobre a família da pessoa com AH/SD. & 8 & $73 \%$ \\
\hline Recursos financeiros. & 8 & $73 \%$ \\
\hline Veículo para atendimentos fora do NAAH/S. & 8 & $73 \%$ \\
\hline Materiais de consumo. & 7 & $63 \%$ \\
\hline Parcerias com as universidades. & 7 & $63 \%$ \\
\hline Supervisão profissional. & 7 & $63 \%$ \\
\hline Espaço físico. & 6 & $54 \%$ \\
\hline Bibliografia especializada. & 5 & $45 \%$ \\
\hline Computadores, impressoras, data show e outros equipamentos eletrônicos. & 5 & $45 \%$ \\
\hline Outros. & 2 & $18 \%$ \\
\hline
\end{tabular}

Garcia (2013) salienta que a oferta de atendimento ao público-alvo da educação especial privilegia as SRM e que os cursos de formação promovidos pelo MEC estão "diretamente articulados ao Programa de Implantação de Sala de Recursos Multifuncionais” (p. 103), cuja proposta é proporcionar a formação do professor de educação especial por meio da prática docente, esvaziando-a de sua base teórica e de seu conteúdo pedagógico, o que leva a uma formação docente superficial.

Pérez e Freitas (2011), ao analisar as instituiçôes de ensino superior, componentes da Rede de Formação Continuada de Professores em Educação Especial, que ofertam cursos em AEE, verificaram

[...] até novembro de 2010, dos três cursos de Especialização (que são os que deverão incluir o Módulo de $\mathrm{AH} / \mathrm{SD}$ ) somente dois já estão em andamento (UFC e UNESP-Marília), Nenhum deles oferece módulo específico sobre Altas Habilidades/Superdotação. (p. 118).

Considerando-se que, como já destacado, apenas $27 \%$ da população informou que os profissionais da UAF participaram de formação específica para atendimento à família de alunos com AH/SD em dois cursos ofertados pelo MEC em anos anteriores, pode-se afirmar que não somente o atendimento à família, mas também o NAAH/S, como um todo, não está recebendo a atenção devida do MEC e das secretarias estaduais. Acrescente-se ainda, os conhecimentos dos profissionais estão sendo construídos apenas com base na prática profissional, não se permitindo o aprofundamento teórico, realidade que vem reforçar as atuais propostas de formaçáo de professores em programas do MEC, tăo bem discutidas por Garcia (2013).

Possivelmente, a procura por capacitação depende do interesse e responsabilidade de cada profissional. Como a oferta de cursos de especialização lato sensu e programas stricto sensu são limitados, a formação continuada, de essencial importância para qualquer profissão, constitui-se realmente um entrave na atuação desses profissionais. 
Como dificuldades para o pleno desenvolvimento do trabalho, oito participantes $(73 \%)$ apontaram a falta de recursos financeiros; outros $73 \%$ apontaram a falta de veículo para atendimentos externos. Provavelmente, a falta de veículo para o transporte dos profissionais dificultava açóes como visita às escolas para reunióes, palestras, orientaçôes e atendimento aos professores do ensino comum e das SRM, conforme instrui o Documento Orientador (BRASIL, 2006). Para 63\% dos participantes, as UAF passavam por dificuldades no estabelecimento de parcerias com as universidades e necessitavam de supervisão profissional para um melhor direcionamento do trabalho realizado no serviço, dado também informado por $63 \%$ da população.

A dificuldade em buscar parcerias com as universidades é confirmada pelos estudos de Moreira e Lima (2012) e pelos resultados encontrados por Lyra (2013, p. 109), os quais afirmaram que a necessidade de ampliar parcerias e realizar um trabalho em conjunto com universidades e outras instituiçóes é uma maneira de "[...] expandir as possibilidades de incentivo e apoio aos alunos com AH/SD”.

A carência de recursos financeiros e, possivelmente, a de investimento por parte da instância administrativa do NAAH/S - seja ela estadual ou municipal - e do governo federal, conduzem às dificuldades básicas do funcionamento do serviço, como, por exemplo, a carência de materiais de consumo, dificuldade apontada por $63 \%$ dos participantes, a falta de espaço físico adequado, registrado por $54 \%$ da população, e a dificuldade no acesso a computadores, impressoras, data show, ou outros equipamentos eletrônicos, indicada por $45 \%$ da populaçáo pesquisada.

A escassa publicação especializada na área também foi indicada como dificuldade por $45 \%$ dos participantes do estudo. Outras dificuldades não especificadas foram apontadas por $18 \%$ da populaçáa.

Os resultados acima descritos levaram a compreender que tais dificuldades e necessidades não ocorriam apenas na UAF, mas em todas as unidades dos NAAH/S participantes do estudo. Com exceção da falta de recursos financeiros, físicos e materiais, verificou-se que as demais dificuldades ou necessidades podiam estar relacionadas à escassez de parceria com as universidades, o que confirma os estudos de Moreira e Lima (2012).

Considerou-se que essas parcerias poderiam colaborar para a ampliação de pesquisas, criação de projetos de extensão, elaboração de cursos e palestras para família, profissionais e comunidade em geral acerca da área das AH/SD, sendo tais parcerias consideradas "[...] como um polo de construção do conhecimento e de interface com a universidade" (MOREIRA; LIMA, 2012, p. 144).

Sobre a formação continuada para os profissionais da UAF dos NAAH/S, também foi perguntado aos participantes se tal formação poderia contribuir para a superação das dificuldades e necessidades que esses profissionais estavam vivenciando.

O Gráfico 2 mostra que, para 27\% dos participantes, a formação continuada resolveria totalmente suas dificuldades e necessidades. Grande parte dos participantes (55\%) destacou que a formação seria muito importante para que as dificuldades fossem solucionadas. Para $9 \%$ da população, a oferta de formação continuada contribui- 
ria, em parte, para a resolução dos problemas vivenciados, e $9 \%$ informaram que as dificuldades e necessidades não seriam resolvidas por meio da formação continuada dos profissionais da UAF.

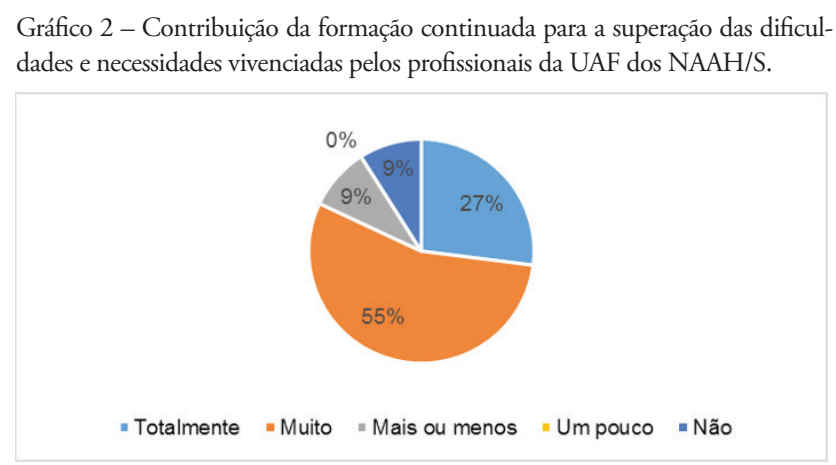

Os dados são compreensivos porque muitas das dificuldades da unidade (talvez de todo o NAAH/S) dependem do incentivo dos órgãos responsáveis, ou seja, de investimento financeiro e material. Boa parte das dificuldades estão relacionadas à questáo da formação profissional e, certamente, à participaçáo em cursos de formação que abordam as diversas áreas de atendimento, ou seja, o aluno, a escola e a família contribuirão para que o serviço alcance suas metas e objetivos.

Talvez, o favorecimento de troca de experiências entre os diferentes NAAH/S também contribua para o crescimento e desenvolvimento das três unidades de atendimento nos diversos estados brasileiros. Lyra (2013) sugere a criação de espaços de discussão entre os NAAH/S a fim de se propiciar a troca de informaçóes, experiências e dados estatísticos oficiais sobre identificação, encaminhamento e atendimento dos alunos ao serviço, visando o seu crescimento e a ampliação. Acrescenta-se também a importância de, nesses momentos, serem observados e analisados dados referentes ao atendimento à família, referentes também as suas contribuiçôes para o serviço e para a solução das dificuldades.

\section{Considerações finais}

Foi possível observar que as UAF e, possivelmente os NAAH/S, vivenciavam dificuldades financeiras, de equipamentos, materiais e de formação profissional. Fazse necessário refletir sobre quais estratégias poderiam ser realizadas para a superação dessas dificuldades, o que contribuiria para o prosseguimento do trabalho e evitaria que este fosse impedido ou que não fossem realizadas em razão de tais dificuldades.

A carência de parcerias com instituiçóes de ensino superior, apesar dos NAAH/S estarem localizados em regiōes que possuem várias universidades (MOREIRA; LIMA, 2012), dificulta a produção de conhecimentos e a promoção de cursos, palestras, grupo de estudos, tanto para os profissionais que atuam no serviço quanto para os familiares do aluno e a comunidade escolar. Esse fato deve ser seriamente discutido, pois os dados evidenciaram que existem UAF que possuíam apenas um ou dois profissionais para dar conta dos objetivos estabelecidos pelo Documento Orientador 
(BRASIL, 2006). Ademais, é possível que esse profissional estivesse sozinho em seu estado ou município e, possivelmente, náo tivesse com quem discutir as açóes a serem tomadas. A oferta de encontros nacionais dos profissionais das unidades, ou dos NAAH/S, conforme já sugerido por Lyra (2013) também poderiam contribuir para a troca de informaçôes, experiências e estudos que, consequentemente, favoreceria o desenvolvimento do trabalho já realizado.

A ausência de cursos específicos que abordem o atendimento à família da pessoa com AH/SD e a falta de incentivo e apoio dos governos estaduais/municipais e federal levam a deduzir que os profissionais do NAAH/S, ou os próprios NAAH/S, estão esquecidos, especialmente quando se observa a promoção, por parte do governo federal, de cursos para professores direcionados mais para o atendimento nas SRM.

É fundamental que os governos federal e estaduais incentivem e cobrem açóes para que parcerias entre os núcleos e as universidades sejam mais consistentes e frequentes, beneficiando os pesquisadores, os profissionais da área e os alunos com AH/ SD possibilitando também maiores investimentos na pesquisa, na formação de pessoal, na proximidade dos alunos com laboratórios, estudos científicos e troca de experiências, conforme instrui o Documento Orientador (BRASIL, 2006).

Espera-se que novas pesquisas científicas sejam direcionadas para a família da pessoa com $\mathrm{AH} / \mathrm{SD}$ e o atendimento que lhes é oferecido. Essa ação poderá contribuir para o crescimento de estudos na área e para favorecer a atuação dos profissionais que estấo nessa empreitada, especialmente aos que estáo na UAF.

\section{Referências}

ASPESI, C. C. A família do aluno com altas habilidades/superdotaçấo. In: FLEITH, D. S. (Org.). A construção de práticas educacionais para alunos com altas habilidades/superdotaçáo: o aluno e a família. Brasília: MEC/SEESP, 2007. v. 3, p. 29-47.

BABBIE, E. Métodos de pesquisa de survey. Traduçáo de Guilherme Cezarino. 3. ed. Belo Horizonte: Ed. UFMG, 2005.

BARDIN, L. Análise de conteúdo. Lisboa: Ediçōes 70, 1977.

PÉREZ, S. G. P. O atendimento educacional ao aluno com altas habilidades/ superdotação na legislação da região sul do Brasil: os lineamentos para concretizar uma quimera. In: FREITAS, S. N. (Org.). Educaçáo e altas habilidades/superdotaçáo: a ousadia de rever conceitos e práticas. Porto Alegre: UFSM, 2006. p. 151-197.

PÉREZ, S. G. P.; FREITAS, S. N. Encaminhamentos pedagógicos com alunos com altas habilidades/superdotação na educação básica: o cenário brasileiro. Educar em Revista, Curitiba, n. 41, p. 109-124, jul./set. 2011.

BRASIL. Decreto $N^{\circ}$ 7.611, de 17 de novembro de 2011. Dispóe sobre a educação especial, o atendimento educacional especializado e dá outras providências. Brasília, DF, 2011. Disponível em: <http://www.planalto. gov.br/ccivil_03/_ato2011-Decreto/D7611.htm\#art11>. Acesso em: 21/08/2012.

Núcleo de Atividades de Altas Habilidades/Superdotação - NAAHS. Documento Orientador. Brasília: MEC/SEESP, Brasil, 2006. Disponível em: <http:www.mec.gov.br> Acesso em: 09/09/2012.

BRASIL. Ministério da Educação. Secretaria de Educação Especial. Política Nacional de Educação Especial na Perspectiva da Educação Inclusiva. Inclusáo: Rev. Educ. Esp., Brasília, v. 4, n. 1, p. 1-61, jan./jun. 2008. Ed. Especial. Disponível em: <http://portal.mec.gov.br/seesp/arquivos/pdf/revinclusao5.pdf>. Acesso em: 07/02/2013.

Projeto político pedagógico de curso de especializaçáo lato sensu em atendimento educacional especializado - AEE. Brasília: MEC/SEESP, 2009/2010. 
CIANCA, F. S. C.; LYRA, J. C.; MARQUEZINE, M. C. A produção científica sobre altas habilidades/ superdotação contida nos periódicos indexados. In: CONGRESSO BRASILEIRO DE EDUCAÇÃO ESPECIAL, 4., 2010, São Carlos. Anais... São Carlos: UFSCAR, 2010.

GARCIA, R. M. C. Política de educação especial na perspectiva inclusiva e a formação docente no Brasil. Revista Brasileira de Educaçáo, Rio de Janeiro, v. 18, n. 52, p. 101-239, jan./mar. 2013.

LYRA, J. C. Atendimento educacional especializado de alunos com altas habilidades/superdotaçáo na cidade de Londrina, Paraná: um estudo de caso. 2013. Dissertaçáo (Mestrado em Educaçáo) - Universidade Estadual de Londrina, Londrina, 2013.

MARQUEZINE, M. C. Formaçáo de profissionais/professores de Educação Especial-deficiência mental e curso de pós-graduaçáo lato sensu: um estudo de caso. 2006. Tese (Doutorado em Educaçáo) - Universidade Estadual Paulista Júlio de Mesquita Filho - UNESP, Marília, 2006

MOREIRA, L. C.; LIMA, D. M. M. P. Interface entre os Naah/s e Universidade: um caminho para inclusão de alunos com altas habilidades/superdotaçăo. In: MOREIRA, L. C.; STOLTZ, T. (Orgs.). Altas habilidades/ superdotaçáo, talento, dotaçáo e educaçáo. Curitiba: Juruá Editora, 2012. p. 143-153.

PROPOSTA de Lei da Câmara $N^{\circ} 31$ de 2010. Propóe a regulamentação da profissão de psicopedagogo. Elaborado pela deputada professora Raquel Teixeira. Disponível em: <http://www.senado.gov.br/atividade/materia/detalhes.asp?p_cod_mate=96399>. Acesso em: 20/09/ 2013.

SAKAGUTI, P. M. Y.; BALSANELLO, M. A. A família e o aluno com altas habilidades/superdotação. In: MOREIRA, L. C.; STOLTZ, T. (Orgs.). Altas habilidades/Superdotaçáo, talento, dotaçáo e educaçáo. Curitiba: Juruá Editora, 2012. p. 221-235.

SILVA, P. V. C.; FLEITH, D. S. A influência da família no desenvolvimento da superdotação: a família e o indivíduo superdotado. Revista Semestral da Associaçáo Brasileira de Psicologia Escolar e Educacional ABRAPEE. v. 12, n. 2, p. 377-346, jul./dez. 2008.

\section{Notas}

${ }^{1}$ Instituição financiadora: CAPES.

\section{Correspondência}

Viviane Tramontina Leonessa - Núcleo de Atividades de Altas Habilidades/Superdotação, Coordenação da Unidade de Apoio a Família. Av. Juscelino Kubitschek, 2372. Centro, 86020-000 - Londrina, Paraná - Brasil.

E-mail: vivitramontina@gmail.com - mcrismarquezine@gmail.com

Recebido em 21 de janeiro de 2016

Aprovado em 10 de março de 2016 